\title{
A NEW SOLID MEDIUM FOR ISOLATING AND ENUMERATING THIOBACILLUS FERROOXIDANS
}

\author{
PAOLO VISCA, ${ }^{*}$ EMMA BIANCHI, MARIO POLIDORO, \\ VINCENZO BUONFIGLIO, PIERA VALENTI, ${ }^{1}$ \\ AND NICOLA ORSI \\ Istituto di Microbiologia, Universita' di Roma "La Sapienza," \\ P.le A. Moro 5, 00185 Roma, Italy \\ ${ }^{1}$ Istituto di Microbiologia, Universita' di Napoli, \\ Larghetto S. Aniello a Caponapoli 80126 Napoli, Italy
}

(Received December 13, 1988)

\begin{abstract}
The growth of seven Thiobacillus ferrooxidans strains was trested on various solid media prepared according to previously published procedures in comparison with a series of new formulations (TSMs, Thiobacillus solid media) set up in our laboratory. These media differed in the type of gelling agent and in the concentration of phosphate and ferrous ions. It was determined that the established formulations brought qualitatively and quantitatively unsatisfactory results whereas, among the new media, TSM 1 produced quantitative yields of $T$. ferrooxidans colonies. The TSM 1 supports the growth of $T$. ferrooxidans strains and can be recommended for the estimation of cell numbers in liquid cultures and for the isolation of single clones. There was also a noticeable similarity in the morphology of colonies formed by different $T$. ferrooxidans strains.
\end{abstract}

The chemoautotrophic bacterium Thiobacillus ferrooxidans is able to obtain energy from the oxidation of ferrous iron and/or inorganic sulfur compounds. An important feature of this extremophile is its ability to grow and reproduce readily at the lower extremes of the $\mathrm{pH}$ scale (1.5-2.0)(3).

Studies of the biochemistry and physiology of this microorganism have been stimulated by the ever increasing development of the bioleaching processes that are used industrially to recover metals from ores and to desulphurize coal $(2,11)$. In spite of this interest in $T$. ferrooxidans, and its genetic improvement for biomining operations (15) much work has still to be done to select efficient strains for making the leaching systems commercially feasible. The lack of studies of the genetic manipulation of this bacterium is mainly concerned with the difficulty of applying

* Address reprint requests to: Dr. Paolo Visca, Istituto di Microbiologia, Universita' di Roma "La Sapienza," Piazzale A. Moro 5, 00185 Roma, Italy. 
the usual genetic techniques; a crucial step for selection and screening of clones is to obtain growth of $T$. ferrooxidans on solid media. So, the development of a solid medium suitable for the growth of $T$. ferrooxidans represents a fundamental step in the standardization of the biological procedures required for better phenotypic and genetic characterization of this chemolithotrophic acidophile.

Various media have been developed to cultivate this microorganism on a solid surface. Tuovinen and Kelly(13) proposed a membrane filter technique on ferrous-iron agar (containing Japanese agar as a gelling agent). This has unsatisfactory results because of the weak consistence of the gel and the low colony production, as reported by the authors. Manning (5) devised ISP (iron-salts-purified agar) medium containing Oxoid purified agar L28 on which not all the strains of T. ferrooxidans are able to grow. Moreover, this medium does not give reliable results because the dark spots that appear after plating $T$. ferrooxidans on it do not represent real single colonies but aggregates of mineral precipitates and cell clumps, as successively reported by Harrison(1). Mishra et al. (7) described some Manning-like media using Bapco agar, agarose and carrageenan as gelling agents. Harrison ( $I)$ has proposed the two-layer gel in order to avoid surface mineral deposition. This medium has the disadvantage of being very laborious and time consuming and the two-layer gel prevents an appropriate oxygen diffusion which is a condition necessary for the growth of $T$. ferrooxidans.

More recently, Johnson et al.(4) studied the factors influencing the colony growth of acidophilic heterotrophic bacteria and $T$. ferrooxidans on solid media, and Schrader and Holmes (10) developed two formulations suitable to detect colony morphology variants among $T$. ferrooxidans strains.

In this paper we describe the development of a new solid medium on which the tested $T$.ferrooxidans strains can produce discrete and easily countable colonies. Also, this medium is compared with the solid media described by Tuovinen and Kelly (13), Manning (5) and Mishra et al. (7).

\section{MATERIALS AND METHODS}

Bacterial strains. The T. ferrooxidans strains ATCC 33020 and NCIB 8455 were obtained from the American Type Culture Collection, Maryland, U.S.A. and the National Collection of Industrial Bacteria, Aberdeen, Scotland. In addition, five strains of $T$. ferrooxidans isolated from different sources in the same geographic area of the outskirts of Rome were also used. These strains are named according to their isolation sites, i.e. the strain TFOB was drawn from soil, TFOF from a stream, and TFOS, TFVS and TFMSR from different sulfuric springs. A detailed characterization of these strains has been reported previously by Visca et al. (14).

Media and growth conditions. The strains were routinely cultivated in $9 \mathrm{~K}$ liquid

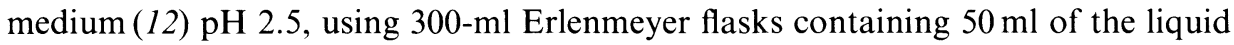
medium. The flasks were inoculated with approximately $2 \times 10^{6}$ cells of $T$. ferrooxidans per $\mathrm{ml}$ and incubated at $30^{\circ} \mathrm{C}$ on a rotary shaker (New Brunswick 
mod. G25) at $250 \mathrm{rpm}$ until the stationary phase was reached.

Four new Thiobacillus solid media (TSM 1, 2, 3 and 4) were prepared by combining three separately sterilized solutions. Solution A, basal salts: $3.0 \mathrm{~g}$ of $\left(\mathrm{NH}_{4}\right)_{2} \mathrm{SO}_{4}, 0.1 \mathrm{~g} \mathrm{KCl}, 0.05 \mathrm{~g} \mathrm{~K}_{2} \mathrm{HPO}_{4}, 0.5 \mathrm{~g} \mathrm{MgSO}_{4} \cdot 7 \mathrm{H}_{2} \mathrm{O}, 0.015 \mathrm{~g} \mathrm{Ca}\left(\mathrm{NO}_{3}\right)_{2} \cdot$ $4 \mathrm{H}_{2} \mathrm{O}$ dissolved in this order in $600 \mathrm{ml}$ of distilled water, acidified with $\mathrm{H}_{2} \mathrm{SO}_{4}$ to $\mathrm{pH} 2.5$ and autoclaved at $121^{\circ} \mathrm{C}$ for $15 \mathrm{~min}$ and cooled to $60^{\circ} \mathrm{C}$. Solution $\mathrm{B}$ : $\mathrm{FeSO}_{4} \cdot 7 \mathrm{H}_{2} \mathrm{O} 22.0 \mathrm{~g}$ dissolved in $150 \mathrm{ml}$ of distilled water acidified to $\mathrm{pH} 2.5$, filter-sterilized and warmed to $60^{\circ} \mathrm{C}$. Solution C: $5 \mathrm{~g}$ gelling agents in $250 \mathrm{ml}$ of

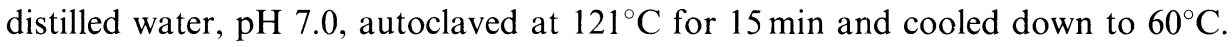
The TSM media differ in their gelling agent: agarose Biorad High mr 162-0001, agarose LKB 2206-101, agar Bios Special LL 1030 and agar Oxoid L11 were used respectively in TSM 1, TSM 2, TSM 3 and TSM 4. Solution A was gently mixed with solution $\mathrm{B}$ and then solution $\mathrm{C}$ was added to this combination and well mixed. The mixture was then poured immediately into pre-warmed Petri dishes. The solid media obtained are sufficiently firm for spreading the inoculum with a glass rod.

After the spreading of $10 \mu \mathrm{l}$ of the appropriate dilution of the liquid culture in $0.01 \mathrm{~N} \mathrm{H}_{2} \mathrm{SO}_{4} \mathrm{pH} 2.5$, the plates were inverted and incubated in a moist atmosphere of $5 \% \mathrm{CO}_{2}, 15 \% \mathrm{O}_{2}$ and $80 \% \mathrm{~N}_{2}$ at $28-30^{\circ} \mathrm{C}$ for $7-10$ days. After this period purple colonies were present on the surface of the medium thus allowing counting.

In addition, we developed a 9K solid medium, prepared by adding agarose Biorad High mr 162-0001 as the gelling agent to a modified 9K liquid medium (12). The medium is composed of three solutions. Solution A: basal salts $3.0 \mathrm{~g}$ of $\left(\mathrm{NH}_{4}\right)_{2} \mathrm{SO}_{4}, 0.1 \mathrm{~g} \mathrm{KCl}, 0.5 \mathrm{~g} \mathrm{~K}_{2} \mathrm{HPO}_{4}, 0.5 \mathrm{~g} \mathrm{MgSO}_{4} \cdot 7 \mathrm{H}_{2} \mathrm{O}, 0.01 \mathrm{~g} \mathrm{Ca}\left(\mathrm{NO}_{3}\right)_{2} \cdot 4 \mathrm{H}_{2} \mathrm{O}$ dissolved in $500 \mathrm{ml}$ of distilled water, autoclaved at $121^{\circ} \mathrm{C}$ for $15 \mathrm{~min}$ and cooled to $70^{\circ} \mathrm{C}$. Solution B: $\mathrm{FeSO}_{4} \cdot 7 \mathrm{H}_{2} \mathrm{O} 33.0 \mathrm{~g}$ dissolved in $300 \mathrm{ml}$ of distilled water adjusted with $1 \mathrm{ml}$ of $10 \mathrm{~N} \mathrm{H}_{2} \mathrm{SO}_{4}$ to $\mathrm{pH} 2-3$ and filter-sterilized. Solution C: agarose Biorad High $\mathrm{mr} 162-0001,10 \mathrm{~g}$ in $200 \mathrm{ml}$ of distilled water, autoclaved at $121^{\circ} \mathrm{C}$ for $15 \mathrm{~min}$. The solutions were added in that order, well mixed and $15 \mathrm{ml}$ were quickly poured into $9 \mathrm{~cm}$ Petri dishes. The media described by Tuovinen and Kelly (13), Manning (5) and Mishra et al. (7) were prepared exactly as described by the authors. The chemical composition is reported in Table 1.

Determination of viable cell numbers. The amount of cells in liquid cultures was determined by direct microscopic counts, using a Petroff-Hauser counting chamber. The values derived from microscopic counts were compared with the number of colony-forming units (C.F.U.) as determined according to the dilution plating method. In addition, the number of $T$. ferrooxidans cells per colony was estimated as follows: ten twelve-days old colonies of each strain were cut off from the gel, disrupted in a Dounce homogenizer using a B-type pestel and counted according to the spread-plate method.

Determination of iron oxidation. The iron oxidation in liquid cultures was estimated volumetrically by the titration of residual ferrous ions with $0.1 \mathrm{~N} \mathrm{KMnO}_{4}$. The ferric ion content was also determined by the Schnaitman et al. method (9) using a standard curve calibrated with known quantities of $\mathrm{FeCl}_{3} \cdot 6 \mathrm{H}_{2} \mathrm{O}$. 
Table 1. Chemical composition of the solid media used.

\begin{tabular}{|c|c|c|c|c|c|}
\hline \multirow[b]{2}{*}{ Chemicals } & \multicolumn{5}{|c|}{ Media } \\
\hline & $\begin{array}{l}\text { Modified 9K } \\
\text { solid medium }\end{array}$ & $\begin{array}{l}\text { Tuovinen and } \\
\text { Kelly } \\
(1973)\end{array}$ & $\begin{array}{c}\text { Manning } \\
\text { (1975) }\end{array}$ & $\begin{array}{l}\text { Mishra } \\
\text { et al. } \\
\text { (1983) }\end{array}$ & TSM \\
\hline \multicolumn{6}{|c|}{ A: Basal salts solution (g) } \\
\hline$\left(\mathrm{NH}_{4}\right)_{2} \mathrm{SO}_{4}$ & 3.0 & 1.6 & 6.0 & 3.0 & 3.0 \\
\hline $\mathrm{KCl}$ & 0.1 & / & 0.2 & 0.1 & 0.1 \\
\hline $\mathrm{K}_{2} \mathrm{HPO}_{4}$ & 0.5 & 1.6 & 1 & 1 & 0.05 \\
\hline $\mathrm{MgSO}_{4} \cdot 7 \mathrm{H}_{2} \mathrm{O}$ & 0.5 & 1.6 & 1.0 & 0.5 & 0.5 \\
\hline $\mathrm{Ca}\left(\mathrm{NO}_{3}\right)_{2} \cdot 4 \mathrm{H}_{2} \mathrm{O}$ & 0.01 & / & 0.02 & 1 & 0.015 \\
\hline $10 \mathrm{~N} \mathrm{H}_{2} \mathrm{SO}_{4}$ & $1 \mathrm{ml}$ & 1 & 1 & 1 & 1 \\
\hline Distilled $\mathrm{H}_{2} \mathrm{O}$ & $500 \mathrm{ml}$ & $250 \mathrm{ml}$ & $550 \mathrm{ml}$ & $550 \mathrm{ml}$ & $600 \mathrm{ml}$ \\
\hline $\mathrm{pH}$ & 2.5 & 1.55 & 3.0 & 3.0 & 2.5 \\
\hline \multicolumn{6}{|c|}{ B: Ferrous sulfate solution $(\mathrm{g})$} \\
\hline $\mathrm{FeSO}_{4} \cdot 7 \mathrm{H}_{2} \mathrm{O}$ & 33.0 & 133.2 & 33.4 & 10 & 22.0 \\
\hline Distilled $\mathrm{H}_{2} \mathrm{O}$ & $300 \mathrm{ml}$ & $250 \mathrm{ml}$ & $300 \mathrm{ml}$ & $300 \mathrm{ml}$ & $150 \mathrm{ml}$ \\
\hline $\mathrm{pH}$ & 2.5 & 1.55 & 2.5 & 2.5 & 2.5 \\
\hline \multicolumn{6}{|c|}{ C: Gelling solution $(\mathrm{g})$} \\
\hline & Agarose & Difco Bacto & Purified Agar & Agarose & 1-Agarose \\
\hline & $\begin{array}{l}\text { Biorad } \\
\text { High mr }\end{array}$ & Agar & L28 Oxoid & Sigma & $\begin{array}{l}\text { Biorad } \\
\text { High mr } \\
\text { 2-Agarose LKB } \\
\text { 3-Agar Bios } \\
\text { 4-Agar Oxoid }\end{array}$ \\
\hline & 10 & 4.0 & 7.0 & 6.0 & 5.0 \\
\hline Distilled $\mathrm{H}_{2} \mathrm{O}$ & $200 \mathrm{ml}$ & $500 \mathrm{ml}$ & $150 \mathrm{ml}$ & $150 \mathrm{ml}$ & $250 \mathrm{ml}$ \\
\hline
\end{tabular}

Determination of free reducing sugars. Nelson's method $(8)$ was used to determine free reducing sugars.

Five $\mathrm{ml}$ of distilled water was poured onto the surface of Petri dishes containing $15 \mathrm{ml}$ of each solid medium. The plates were incubated overnight at $4^{\circ} \mathrm{C}$ on a rotary shaker (50 rpm); 1-ml samples were collected and supplemented with $100 \mu \mathrm{l}$ of $10 \mathrm{~N}$ $\mathrm{NaOH}$ to precipitate soluble iron that interferes with the test. The iron hydroxides were removed by centrifuging $\left(15,000 \times g, 5 \mathrm{~min}, 4^{\circ} \mathrm{C}\right)$ and the supernatants were neutralized by adding $10 \mathrm{~N} \mathrm{HCl}$. Nelson's test (8) was carried out on $1 \mathrm{ml}$ of the samples and the concentration of free reducing sugars was determined according to a standard curve calibrated with known quantities of glucose in a range of 0.2 and $20 \mu \mathrm{M}$.

Photography. Photomacrographs of colonies were taken directly from inoculated plates using an Ilford FP4 film and a Nikon F2 camera supplied with a Micronikkor 55 lens. The plates were bottom-lighted.

Photomicrographs were obtained by means of a Leitz Dialux Vario-20 EB microscope equipped with a Leitz Ortomat photographic apparatus. 


\section{RESULTS}

\section{Growth of Thiobacillus ferrooxidans on different solid media}

In the first section of the experiment we checked the growth of $T$. ferrooxidans on the solid media described by Tuovinen and Kelly (13), Manning (5), Mishra et al. (7) in comparison with the $9 \mathrm{~K}$ solid medium obtained from a modification of the liquid medium proposed by Silverman and Lundgren(12) and the TSMs supplemented with different gelling agents.

Only TSM 1, TSM 2, TSM 4 and the medium by Tuovinen and Kelly (13) underwent a noticeable modification 10 days after inoculation with $T$.ferrooxidans, as can be seen in Fig. 1. However, these media revealed some important differences. First of all the medium of Tuovinen and Kelly is characterized by an extremely weak gel which impedes the spreading operations, and the appearance of diffused reddish-brown areas can be observed only on plates inoculated with the lowest dilution $\left(10^{-2}\right.$ and $\left.10^{-3}\right)$; therefore the identification of discrete colonies on this medium is not possible. TSM 2, in spite of the better solidity of the gel, does not show any correlation with the numbers of C.F.U. obtained after plating different serial dilutions, so it cannot be used for the enumeration of the microorganisms. TSM 4 , although if allows quantitative yields of $T$. ferrooxidans colonies, has very weak gel consistency. TSM 1 was the most suitable medium because of the solidity of the gel and because it supported the growth of distinct and easily countable colonies even with the highest dilutions $\left(10^{-5}\right.$ and $\left.10^{-6}\right)$ of the inocula (see enumeration results below). Although Fig. 1 shows only the growth of $T$. ferrooxidans TFOS, similar results have been obtained also with the strains TFOB, TFOF, TFVS, TFMSR, ATCC 33020 and NCIB 8455 . The key role played by the gelling agent in conditioning the microbial growth is illustrated in Fig. 2A. In fact, the $T$. ferrooxidans strains tested show excellent growth on the medium containing Biorad agarose (TSM 1), whereas the same strains, except TFVS, failed to grow when plated on the medium containing Bios agar (TSM 3). However the analysis of free reducing sugars released after 10 days of incubation did not reveal any remarkable difference among the eight media tested. (The concentration of free reducing sugars was always lower than $0.2 \mu \mathrm{M}$.)

\section{Morphology of Thiobacillus ferrooxidans colonies on TSM 1}

The colonies formed by five $T$. ferrooxidans strains on TSM 1 did not have any outstanding morphological differences. The colonies are generally circular and concave with regular edges (Fig. 2B). Growth begins with tiny, pale colonies of about $0.2 \mathrm{~mm}$ and continues with the deposition of orange iron oxide. In a few days the colonies become dark brown with a yellow-orange halo. The colonies never become very large and after approximately 10 days are $0.5-0.7 \mathrm{~mm}$ in diameter. The only difference among the five strains is in the size of the colonies; generally, strains TFOF, TFOS and TFMSR form slightly larger colonies than the other strains. Some variations in colony size also occur within the same strain. Based on 

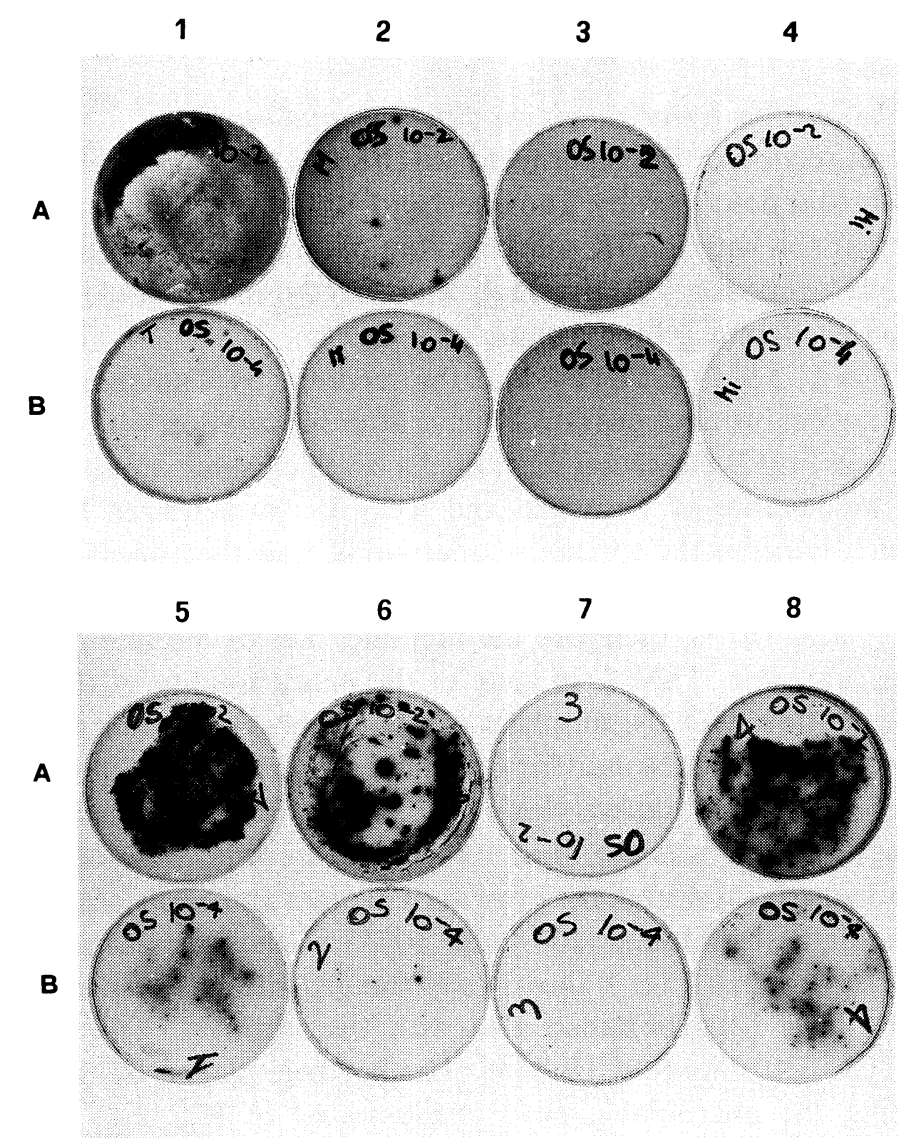

Fig. 1. Growth of Thiobacillus ferrooxidans strain TFOS on different solid media. A: $10^{-2}$ dilution of cell suspension. B: $10^{-4}$ dilution of cell suspension. 1) solid medium proposed by Tuovinen and Kelly; 2) solid medium proposed by Manning; 3) 9K solid medium; 4) solid medium proposed by Mishra et al.; 5) TSM 1;6) TSM 2; 7) TSM 3; 8) TSM 4. The inoculum used for spreading corresponded to $10 \mu \mathrm{l}$.

our calculation, one colony of $T$. ferrooxidans on TSM 1 contains approximately $5 \times 10^{5}$ viable cells. This number conforms with a single-layer condition of bacteria inside the colony.

Use of TSM 1 for the enumeration of Thiobacillus ferrooxidans

TSM 1 was an excellent medium for enumerating viable $T$. ferrooxidans cells. The conventional spreading technique was used and Fig. 3 shows a precise correlation between different dilutions and the number of $T$. ferrooxidans ATCC 33020 colonies grown on the solid medium.

To ascertain the extent of recovery of viable cells in liquid cultures grown in 


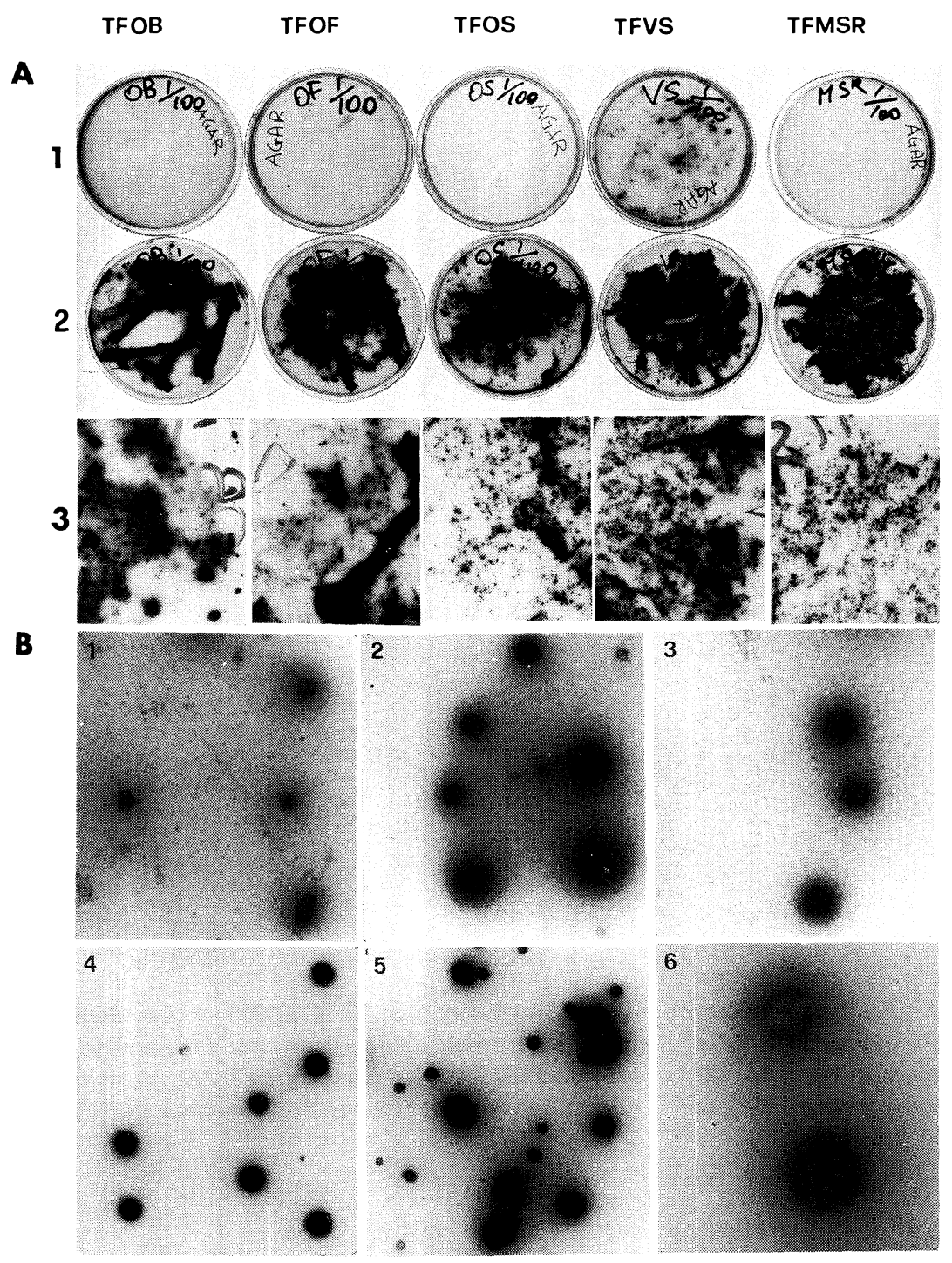

Fig. 2. A: Growth of the Thiobacillus ferrooxidans strains TFOB, TFOF, TFOS, TFVS, and TFMSR on: 1) TSM 3; 2) TSM 1. Plates were inoculated with $10 \mu \mathrm{l}$ of a $10^{-2}$ dilution. 3) Details of the plates shown in A2. B: Photomicrographs of colonies formed by the Thiobacillus ferrooxidans strains (further enlarged: $25 \times$ magnification): 1) TFOB; 2) TFOF; 3) TFOS; 4) TFVS; 5) TFMSR; 6) a more detailed photomicrograph (100× magnification) of two colonies from Thiobacillus ferrooxidans strain TFMSR.

9K medium (12), viable counts were carried out by microscopic enumeration-using a Petroff-Hauser counting chamber-and by plating on TSM 1. As shown in Table 2 , the plate counts were nearly equivalent to the direct microscopic cell counts. This 


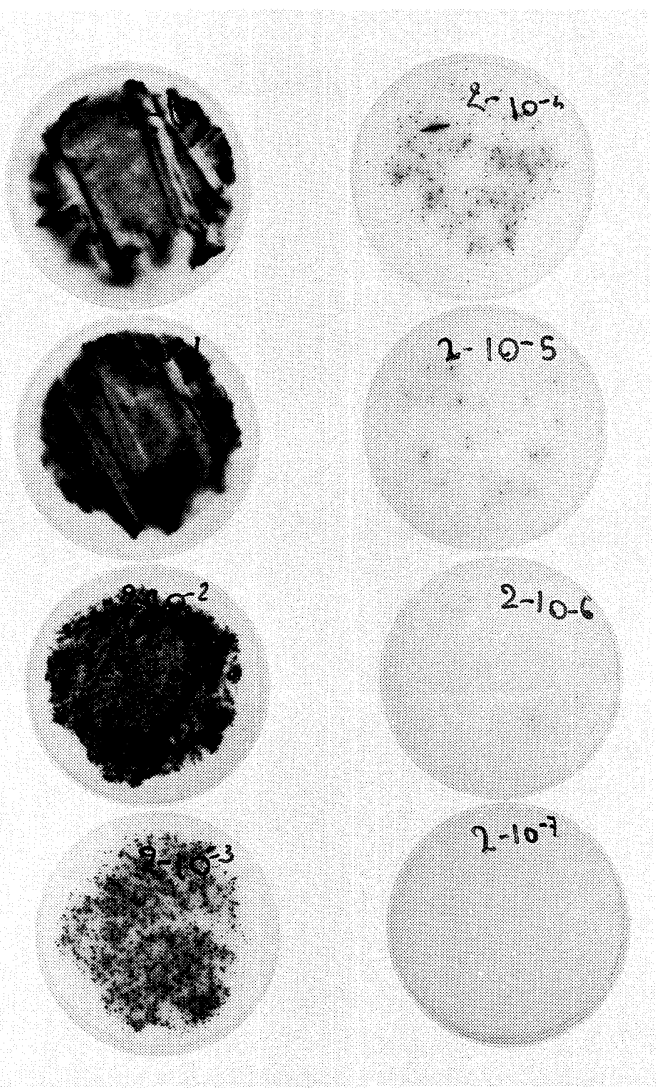

Fig. 3. Enumeration of Thiobacillus ferrooxidans ATCC 33020 by means of dilution plating method on TSM 1 . Ten $\mu$ of serial 10 fold dilutions were used for spreading. Left line from the top to the bottom shows the following dilutions: undiluted culture in $9 \mathrm{~K}$ liquid medium, $10^{-1}, 10^{-2}, 10^{-3}$. Right line from the top to the bottom: $10^{-4}, 10^{-5}$, $10^{-6}, 10^{-7}$.

shows almost complete recovery of viable cells on TSM 1.

Single $T$. ferrooxidans colonies were picked up and their viability was assessed by subculturing them in $9 \mathrm{~K}$ liquid medium. The results show that viable colonies were available on TSM 1 for at least one month after plating.

\section{DISCUSSION}

The present paper concerns the composition of a new solid medium, TSM 1, suitable for the isolation and enumeration of $T$. ferrooxidans. The difficulties encountered in the past in growing $T$. ferrooxidans on solid media were attributed to a number of causes such as the quality and the amount of the gelling agent, the 
Table 2. Comparison of the average number of cells $/ \mathrm{ml}$ obtained by both microscopic and dilution plating counts on TSM 1.

\begin{tabular}{lcc}
\hline Strain & $\begin{array}{c}\text { Direct microscopic counts } \\
\text { Average number } \\
\text { of cells/ml }(\mathrm{SD})\end{array}$ & $\begin{array}{c}\text { Plating counts } \\
\text { Average number } \\
\text { of cells } / \mathrm{ml}(\mathrm{SD})\end{array}$ \\
\hline ATCC 33020 & $2.43( \pm 0.78) \times 10^{8}$ & $2.40( \pm 0.4) \times 10^{8}$ \\
NCIB 8455 & $2.20( \pm 1.05) \times 10^{8}$ & $2.50( \pm 0.3) \times 10^{8}$ \\
TFOB & $4.30( \pm 1.65) \times 10^{8}$ & $4.80( \pm 0.8) \times 10^{8}$ \\
TFOF & $2.50( \pm 1.03) \times 10^{8}$ & $1.80( \pm 0.5) \times 10^{8}$ \\
TFOS & $1.61( \pm 0.76) \times 10^{8}$ & $0.98( \pm 0.2) \times 10^{8}$ \\
TFVS & $1.60( \pm 0.72) \times 10^{8}$ & $2.20( \pm 0.4) \times 10^{8}$ \\
TFMSR & $1.66( \pm 0.60) \times 10^{8}$ & $2.10( \pm 0.5) \times 10^{8}$ \\
\hline
\end{tabular}

The reported data represent mean values ( \pm standard deviation) obtained from the examination of either 80 microscopic fields or 9 different TSM 1 plates for each strain (3 plates for each dilution $\left.10^{-4}, 10^{-5}, 10^{-6}\right)$.

presence of phosphates, the growth conditions and variations among the strains $(4-7,10)$. To establish the relevance of these factors, the growth on solid media of seven $T$. ferrooxidans strains has been tested. Also, the suitability of different gelling agents as well as the influence of phosphate and ferrous iron concentrations on the growth of $T$. ferrooxidans has been investigated.

Comparisons of the different TSMs demonstrated that TSM1 allowed the growth of all of the strains of $T$. ferrooxidans tested and showed the suitability of the agarose Biorad as a gelling agent because of its solidity and high purity. But other gelling agents inhibited the growth of $T$. ferrooxidans, probably due to the presence of impurities, as also suggested in previous reports $(1,4,5,13)$. After a preliminary test for the growth of $T$. ferrooxidans on TSMs supplemented with several types of agar, a positive result was obtained only with the refined bacteriological agar Oxoid L11.

Another major problem in growing $T$. ferrooxidans on a solid medium is the acid $\mathrm{pH}$ which may cause hydrolysis of the gelling agent thus releasing diffusible reducing sugars. In order to find out whether the differences in the colony development on the 8 solid media were due to the presence of toxic-free reducing sugars, the concentration of these sugars determined by Nelson's test (8). Our data showed that no detectable free reducing sugars were released from the solid media.

Regarding phosphate, we found that adding this anion in a low concentration to TSM $1(0.05 \mathrm{~g} / l)$ did not prevent the growth of the colonies. This is in contrast with a previous report by Manning(5) who suggested that the gelling agent may supply enough phosphate to support the growth of the cells and that exogenous addition may have unfavorable effects. It should be stressed that the agarose Biorad we used does not contain phosphates (as specified by the manufacturer) and therefore supplementation with this anion is required to allow the growth of $T$. ferrooxidans colonies. Our observations indicate that the presence of phosphate is essential for 
the growth of T. ferrooxidans. But in agreement with Johnson et al. (4), phosphate concentrations higher than $0.05 \mathrm{~g} / l$ may inhibit the development of the microorganism, as shown by the absence of growth on the modified $9 \mathrm{~K}$ solid medium.

Concerning ferrous sulfate, the concentration chosen was $22 \mathrm{~g} / l$, which is an intermediate value between those proposed by Manning (5) and by Mishra et al. (7). This concentration did not appear to be limiting and allowed a clear visualization of oxidation haloes around the colonies. Iron concentration higher than $25 \mathrm{~g} / l$ inhibited the growth of all the T. ferrooxidans strains tested as Johnson et al. (4) also reported.

Considering all these findings, the new solid medium TSM 1 provides many advantages for the production of discrete and easily countable colonies of $T$. ferrooxidans: it is suitable for the growth of all the strains tested and allowed the development of single colonies after 7-10 days even at the highest inoculum dilutions $\left(10^{-5}\right.$ and $\left.10^{-6}\right)$. Therefore with TSM 1 no adaptation to the solid medium was necessary as previously reported by Mishra et al.(7) and a satisfactory growth was obtained at the first passage. TSM 1 also supports the development of colonies of acidophilic heterotrophs and the growth of these microorganisms can be enhanced by supplementing the medium with $0.1 \%$ glucose and $0.01 \%$ yeast extract (data not shown).

Comparing the data obtained by both microscopic and dilution plating counts we found that TSM 1 provided nearly complete recovery of viable cells with all the $T$. ferrooxidans strains tested. The cell viability in the colonies on this medium did not last longer than one month so it cannot be used for long-term storage of $T$. ferrooxidans. However non-inoculated plates can be stored at $4^{\circ} \mathrm{C}$ for at least one month without any negative effect on the development of colonies.

The colonies grown on TSM 1 did not show any particular difference in shape among the seven strains of $T$. ferrooxidans studied. However among the seven strains and within the same strain there were some variations in the dimension of the colonies. At present, we cannot explain this type of colony variation, which is particularly evident in the early stages of growth on TSM1. Preliminary experiments carried out in our laboratory did not show any correlation between dimension and the metabolic activity of the colonies.

Colonies appeared quite dry, opalescent and concave; this may be ascribed to the deposition of iron oxides forming a thin mineral layer that impedes the diffusion of the water inside the colony. Much has been written about the different types of colonies of $T$. ferrooxidans; Manning(5) reported a particular morphology in connection with the secondary growth; Mishra et al. (7) referred to different types of colonies related not only to secondary growth and different nutrient conditions, but also to the strain plated; Schrader and Holmes (10) observed morphology variants of $T$. ferrooxidans grown on two discrete sulfur-iron solid media. These variations did not occur when we plated five of our $T$. ferrooxidans isolates characterized by phenotypic and genetic differences (14) on TSM 1. Similar colony morphology appeared in other T. ferrooxidans strains such as ATCC 33020 and 
NCIB 8455. It is significant that the morphology of T. ferrooxidans NCIB 8455 colonies reported by Mishra et al.(7) using a Manning-like solid medium and by Johnson et al. (4) is practically identical to the general morphological characteristics of all of the strains used in this work.

In conclusion, a solid medium such as TSM 1, can be most advantageous both for isolating pure clones of the iron oxidizer $T$. ferrooxidans and cell counting. Therefore it can be very useful for isolating new mutants, for determining nutritional requirements and for screening particular metabolic activities. At present we have used TSM 1 successfully to evaluate the minimal inhibitory concentration (MIC) of several heavy metals towards $T$. ferrooxidans in order to develop selective markers to discriminate among genetically inherited strains (manuscript in preparation).

\section{REFERENCES}

I) Harrison, A. P., Jr., The acidophile Thiobacilli and other acidophilic bacilli that share their habitat. Annu. Rev. Microbiol., 38, 265-292 (1984).

2) Hutchins, S. R., Davidson, M. S., Brierley, J. S., and Brierley, C. L., Microorganisms in reclamation of metals. Ann. Rev. Microbiol., 40, 311-336 (1986).

3) Ingledew, W. J., Thiobacillus ferrooxidans; the bioenergetics of an acidophilic chemolitotroph. Biochim. Biophys. Acta, 683, 89-117 (1982).

4) Johnson, D. B., Macvicar, J. H. M., and Rolfe, S., A new solid medium for the isolation and enumeration of Thiobacillus ferrooxidans and acidophilic heterotrophic bacteria. J. Microbiol. Methods, 7, 9-18 (1987).

5) Manning, H. L., New medium for isolating iron-oxidizing and heterotrophic acidophilic bacteria from acid mine drainage. Appl. Microbiol., 30, 1010-1016 (1975).

6) Mishra, A. K. and Roy, P., A note on the growth of Thiobacillus ferrooxidans on solid medium. J. Appl. Bacteriol, 47, 289-292 (1979).

7) Mishra, A. K., Roy, P., and Mahapatra, S. S. R., Isolation of Thiobacillus ferrooxidans from various habitats and their growth pattern on solid medium. Curr. Microbiol., 8, 147-152 (1983).

8) Nelson, N., Colorimetric method for determination of sugars. J. Biol. Chem., 153, 375-380 (1944).

9) Schnaitman, C. A., Korckzynsky, M. S., and Lundgren, D. G., Kinetic studies of iron oxidation by whole cells of Thiobacillus ferrooxidans. J. Bacteriol., 99, 552-557 (1969).

10) Schrader, J. A. and Holmes, D. S., Phenotypic switching of Thiobacillus ferrooxidans. J. Bacteriol., 170, 3915-3923 (1988)

11) Scott, C. D., Strandberg, G. W., and Lewis, S. N., Microbial solubilization of coal. Biotechnol. Prog., 2, 131-139 (1986).

12) Silverman, M. P. and Lundgren, D. G., Studies on the growth of Thiobacillus ferrooxidans. I. An improved medium for harvesting procedure for securing high cell yields. J. Bacteriol., 77, 642-647 (1959).

13) Tuovinen, O. H. and Kelly, D. P., Studies on the growth of Thiobacillus ferrooxidans. I. Use of membrane filters and ferrous iron agar to determine viable numbers, and composition with ${ }^{14} \mathrm{CO}_{2}$-fixation and iron oxidation as measures of growth. Arch. Mikrobiol., 88, 285-298 (1973).

14) Visca, P., Valenti, P., Bianchi, E., Cosentino, S., and Orsi, N., Comparative plasmid analysis in Thiobacillus ferrooxidans strains. In Biohydrometallurgy, ed. by Norris, P. and Kelly, D. P., Science and Technology Letters, Kew Surrey (1988), p. 565-568.

15) Woods, D. and Rawlings, D., Molecular genetic studies on the Thiobacilli and the development of improved biomining bacteria. Bio Essays, 2, 8-10 (1985). 